\title{
A COMPARATIVE STUDY OF ECONOMIC SPACE BETWEEN LUOYANG CITY IN HAN AND WEI DYNASTIES AND ROME CITY IN IMPERIAL PERIOD
}

\author{
Jin Lipeng \\ PhD of department history of the Belarusian State University, Minsk, Belarus
}

DOI: https://doi.org/10.31435/rsglobal_ws/31052020/7085

\section{ARTICLE INFO}

Received: 21 March 2020

Accepted: 10 May 2020

Published: 31 May 2020

\section{KEYWORDS}

Luoyang City,

Roman City,

Economic Space.

\begin{abstract}
The author of this article reviews the development of Luoyang City and Rome City from a historical perspective, analyzes the economic development of Luoyang City and Rome City from related historical events, briefly compares the economic development space of the two cities, and provides some suggestions for historians to study ancient city-states.
\end{abstract}

Citation: Jin Lipeng. (2020) A Comparative Study of Economic Space Between Luoyang City in Han and Wei Dynasties and Rome City in Imperial Period. World Science. 5(57), Vol.3. doi: 10.31435/rsglobal_ws/31052020/7085

Copyright: (C) 2020 Jin Lipeng. This is an open-access article distributed under the terms of the Creative Commons Attribution License (CC BY). The use, distribution or reproduction in other forums is permitted, provided the original author(s) or licensor are credited and that the original publication in this journal is cited, in accordance with accepted academic practice. No use, distribution or reproduction is permitted which does not comply with these terms.

China's Han Wei Luoyang City occupies an important position in the history of Chinese ancient city architecture, a masterpiece in the typical Asian ancient architectural complex. The ancient Roman city occupies an important position in the ancient European architectural complex and is a representative of European ancient architectural art. This article compares the economic space of the two cities from the perspective of historical evolution, and provides some suggestions for subsequent researchers.

\section{Economic Space of Luoyang City in Han and Wei Dynasties.}

The economic space of Luoyang City in Han and Wei dynasties mainly includes transportation facilities, warehouses, handicraft workshops, markets and so on.

From the Eastern Han Dynasty, the population of Luoyang City in the Han and Wei dynasties increased, especially in the period of Cao Wei and Northern Wei dynasties, the population was huge and the demand for grain increased.

Luoyang City's domestic water and water transport are mainly through the development and utilization of urban water conservancy facilities represented by Yangqu, and formed its own unique urban water conservancy system. "Water Jing Note" records that "Wei Taihe four years (AD 230) of water, flow three battles, sub-underground stop flow to become a lake, ditch to water, east and west ten li, the lake to water." "Luoyang Jialan Ji" records:" out of the door, seven miles outside the long bridge. The valley is under the city. Yangqu is the east-west large-scale channel in the city. West from the east wall of the inner city of Jianchun gate, it meets the city's water ,700 meters east flow from Jianchun gate outside east through the east wall, has been eastward into the Luo River. There is a stone bridge on the canal, below can pass large ships, near the bridge there is a market, often full warehouse, the canal is mainly used for water transport to enrich the storage. It has played an important role in urban domestic water use, defense, irrigation, flood discharge, water transport and landscaping, and has promoted the urban development of Luoyang and become a model for the development of ancient urban water conservancy facilities in China. The function of Yangqu's "Yan Luotong Cao" was significant in the Eastern Han Dynasty. After the establishment of Luoyang in the Eastern Han Dynasty, with the increasing population of Luoyang, the demand for grain is also increasing day by 
day. At the same time, Luoyang is near by the Guandong area, close to grain production areas, the surrounding rivers are numerous, with large-scale water transport conditions. Therefore, the Eastern Han Dynasty immediately began to solve the water supply and water transport problems. According to documents, the construction of Yangqu in the Eastern Han Dynasty occurred at least three times. Chengdong Yangqu section is the key to the smooth flow of water, but because of the high terrain, often silt serious, affecting the flow of water. Therefore, each dynasty attaches great importance to the dredging of Chengdong Yang Canal. After several repairs of Yangqu, the route and function of the east and west of Yangqu have been determined. In order to ensure the water supply and farmland irrigation in Luoyang city, the Yang Canal in the east of the city is mainly the Yiluo Tong Cao Project. Luoyang and the Central Plains, Jianghuai and other crops of the main production areas more closely linked. At that time Luoyang water transport business road has been quite smooth.

Cao Pi was called the emperor's capital Luoyang, in order to restore and develop the economy destroyed by the war, successively sent Wang Chang, Huan Fan, Sima Zhao, Sima Wang, Hou Shiguang, no Qiu Jian to host Luoyang Tuntian.As a result, water conservancy construction at that time was mostly related to land and water transport. More famous is to rebuild Qianjin Canal and Wulong Canal, and then open a new canal, repair the Dragon Canal (that is, Kowloon Canal).

"Read Shi Fangyu Summary" records:" Chen Xie chisel canal from Luokou, through Gong County to Jiuqu Du, and west to Luoyang Dongyang Gate, will be in Yangqu." Wei Ming Emperor Taihe five years (AD 231), all the water messenger Chen Xie in the original Yang canal on the basis of chiseling Qianjin canal. With the channel of Qianjin canal, the channel of Qianjin canal leads the valley water east through the north of Luoyang city, divides into one branch into the city, then from the north to the east of the city and Yang canal rendezvous, from Yanshi into Luo, in order to increase the water quantity of Luo water. In addition, Chen Xie also presided over the renovation of Qianjin, water diversion field, and achieved great economic benefits.

In addition, from the overall development trend of Luoyang City in the Han and Wei dynasties, although there are war and other factors, but from the Eastern Zhou Dynasty to the Northern Wei Dynasty, the population of Luoyang was generally increasing. Especially in the heyday of the Northern Wei Dynasty, the population of Luoyang City reached its highest peak. "The number of hukou, than the husband Jin Taikang, only times. "The capital division east and west 20 li, north and south $15 \mathrm{li}$, the household more than 109 thousand. This is mainly due to a series of economic, political policies and a stable living environment implemented after the Northern Wei Dynasty moved to Luo. However, the increasing population makes Luoyang City's original water supply facing a great test. Relocation to seek more water has become an unavoidable problem for city managers. In Sui Dynasty, the city was moved to Luoyang city area, and Luoyang city was abandoned gradually. Sui's relocation of the capital, in addition to the destruction of the war on Luoyang, the plight of water is an important factor that can not be ignored. After the relocation, Yi, Luo, Jian, Jian four water systems converge in the Sui and Tang capital Luoyang.

In the southeast suburb of Luoyang City site of the Eastern Han Dynasty, between the south bank of Luohe River after the diversion, Luoyang Han Wei team of the Archaeological Institute of the Chinese Academy of Social Sciences excavated a larger brick and tile kiln factory in the Han Dynasty. A large number of kiln sites were found in kiln factory. Most of the kiln sites belong to the Eastern Han Dynasty and a few belong to the Northern Wei Dynasty. A large amount of cinder accumulation was found at the kiln site, indicating that coal was used as fuel at the kiln site. The kilns were run by the government and the bobbin tiles were used to build Luoyang City in the Eastern Han Dynasty.

The market of Luoyang City of Han Wei Dynasty is mainly located in the residential area of Waiguo City, and all three markets are located in it: the big city is in Xiguo City, including the vast area of the market and its surrounding ten Li Fang. Small market is located in Dongguo City, next to the market is also connected with the Li Fang. Sitong City is located in Nanguo, adjacent to the Luohe Bridge and Siyi Li, is the Yihe River, Luohe River and other countries commodity trading place. In addition, there are also some industrial and commercial areas in the Qitai area of Guo City. Such as Jianchun outside the Chang Man Cang near and so on. The site of the Great City of the Northern Wei Dynasty, located in the city of Xiguo. "Luoyang Jialan Ji" records, located outside the gate of Xiyang, about eight miles around. The east of the city is trade, goods two li, inside all the people are skillful, wealth huge. The city south has the tune, the music law two li, inside the person, the world wonderful prostitute Yan. There is a war in the west of the city, in the people to warm wine industry. There is also 
a quasi-money, two li, rich in Yan. Archaeological excavations in recent years are located in the central and western regions of the region. Found a large number of architectural relics, mainly houses, pits, wells three types. Houses are mostly square, scattered, simple structure, walls are not whitewashed, indoor cave storage items. Unearthed objects mainly to porcelain, there are a large number of imitation of Western Asia glassware porcelain. The site also unearthed a strong glass beads. The large amount of porcelain and glass beads unearthed should be closely related to commercial activities.

\section{Economic space in Rome.}

\section{The economic supply system of Rome during the Empire.}

\section{1) Management.}

At the end of the Republic, the population began to grow markedly, making food in Rome in short supply and must be imported on a large scale. Land transportation is expensive, so most of it is by water.

During the Caesar period, two grain officials were established, and the Augustus period commissioned two elders to set up special financial officers for the praefecti frumenti dandi, from Claudius, in various major ports. In the late Republic, the Government distributed free wheat to the citizens of Rome. After the establishment of the Empire, the system of free supply to some citizens continued, benefiting 15-20 million people.

\section{2) Terminals and transport.}

In the 2nd century B.C., maritime trade activity grew rapidly, and the port system of the city of Rome expanded toward the valley, occupying the area between Mount Avandino and the Tiber River. Entering the Empire, the port of Rome was not enough to cope with the busy transportation. In 42 years Claudius built the new port of Claudius on the Tiber River. During the Turajan period, the market wharf was rebuilt and the Turajan wharf was built. buildings.

On the other hand, due to the busy ocean trade, the city of Rome built a series of port-related

The port of Ostia is the most important port near Rome, from which imported goods enter the city of Rome through the Taibo River.

The city of Rome has a large sea transportation scale, a wide variety of, in addition to wheat, olive oil, wine and other food, but also to meet the city's large number of building activities such as marble building materials.

Warehouse. The city of Rome and the port of Ostia have a large number of warehouses, and the quiet structure, quantity and scale of these storage buildings are import trade in the importance of Rome. The river in the middle of the Taibo River is lined with warehouses. From the end of the 4th century B.C., there was a salt barn at the bottom of Evan Tino and a wine warehouse across the river. In the late 2nd century B.C., garba warehouses were built in marble areas, storing wine and oil, and marble. In the late Republic and early Empire, Lorias warehouses and candle warehouses were built on the banks of the Taibo River in Area 13. Most warehouses are similar in structure, with rooms on all sides of an open-air courtyard, often with multi-storey structures, high entrances and access through stairs or slopes.

The initial warehouse of the Empire was brought under the control of the emperor, mainly storing public grain and also storing retail goods.

Handicrafts. During the period of the Republic, the city of Rome established associations of craft trades, such as gold and silversmiths, carpenters, cobblers, blacksmiths, etc. There are also trade associations and personnel associated with urban public and religious life. The imperial period basically continued the management system and production situation of this handicraft industry. There is still controversy about the function of trade associations, but from the list kept by the Association of Architects, the members are slaves and free people who are free, have higher social status and economic strength, and have high personal freedom. Archaeological discovery of tailor shop site, pottery workshop, shoe workshop, brick workshop, boat workshop, marble workshop.

Commercial premises. The imperial city of Rome was in frequent and large commercial trade with other countries, in addition to food and other imports from the Mediterranean, mostly building materials. There are four main types of commercial premises in the city of Rome: the first is a retail store attached to a large building; the second is a warehouse, some of which include some stores, such as Agrippina's, etc.; and the third is an open-air commercial square, which belongs to a commercialoriented public place, unlike a political and commemorative public space such as the Roman Square. The more famous are Niu Square and Oil Square. The fourth is the market, which is a complex type of architectural complex, including the Livia market, the big market, the Tulajen market and so on. 
Comparative studies. Although there are agricultural areas around the two capitals, most of the food and subsistence needs to be transported from the field because of the large population. The main ways of livelihood of ordinary residents in Luoyang City are agriculture, handicraft industry, commerce and so on. In the handicraft industry, the official handicraft industry accounts for a large proportion and mainly serves the court government. The government adopts the policy of "emphasizing agriculture and restraining business" and the closed urban management mode. The business place is fixed and has strict business hours. Although businessmen accumulate wealth, their social status is not high. The most important industries in Rome are commerce, construction, etc. Most of the demand is from sea to city. As maritime transport was vital to the city of Rome, people engaged in business accumulated a great deal of wealth. The city commercial area is free, the specialized commercial area has been planned, the commercial atmosphere is thick.

In the ancient world of the Mediterranean, commerce and trade played an important role in people's production activities, and people participated in social activities frequently. The early capital of ancient China in the East belongs to the political city, the ancient literature records "the city to defend the monarch ", the merchant's status is low, can not participate in politics as an official, the market is primitive, generally located outside the city, all these all prove the difference between the ancient Mediterranean country region and the ancient Chinese city. The ancient capital city of China has no developed market and no large public activity space for the masses.

Conclusions. Due to the different cultural systems, ancient China attached great importance to agricultural development and suppressed commercial activities, so there was little market activity in the Han and Wei Luoyang cities; while the commercial activities in the ancient Roman city were relatively active. This is the typical difference between Hanwei Luoyang City and ancient Rome.

\section{REFERENCES}

1. Luoyan Gjianlanji (2012). URL: https://www.sbkk88.com/mingzhu/gudaicn/luoyangjialanji/218715.html

2. Henan Zhi (2018): "Three cities, Ma City in the east of the city, there is a stone bridge in front, under the staff to water, can be too big boat". "Always full. Outside the gate". URL: https://max.book118.com/html/2018/0921/6043100140001220.shtm

3. Taiping Royal View. 190 volumes (2020) "Yangqu. East flow through Luoyang in the southeast of the city, and then to Jianchun Gate, to transport Chang Man Cang". URL: https://baijiahao.baidu.com/s?id=1666913304657052310\&wfr=spider\&for $=$ pc

4. Jin Shu Wu Di Ji (2017): "Xianning two years, the end of August Ding, from Taicang in the east, of ten closed in the east west market". URL:

https://www.baidu.com/link?url=pHsOabWKKI_GTaxUXythLkSS7zVht5Q32AyizflztxqzRjy9nAi43eGGF yl2eEhRMJmi0zulPojXd09CaG_\&wd=\&eqid=-ee62c44e00170969000000065ed24b9d

5. Summary of Reading Shi Fang Yu Ji Yao. (2005) URL:

https://www.baidu.com/link?url=mAfgvnbxgzV00vyTGmk8wZ1W51MHq5G00EYsEAprzI20HbLPuiJnalWb

O8wXO_FOajCk0MWpjjdTn6pjoH0ZLK\&wd=\&eqid=eaff4afe0005d5db000000065ed24c73

6. Han Wei Luoyang City discovered the East Han coal burning kiln site, Archaeology 19972. 